\title{
Nickel(II) and palladium(II) chelates of dehydroacetic acid Schiff bases derived from thiosemicarbazide and hydrazinecarbodithioate
}

\author{
Abdulla Al Kubaisi ${ }^{1}$ and Kamal Z. IsmaIl \\ Department of Chemistry, Faculty of Science, University of Qatar, Box 2713, Doha-Qatar \\ Received July 16, $1993^{2}$
}

\begin{abstract}
Abdulla Al Kubaisi and Kamal Z. Ismail. Can. J. Chem. 72, 1785 (1994).
Dehydroacetic acid Schiff bases DAE (1) and DATS (2) were isolated from the reaction of dehydroacetic acid (2-acetyl-5hydroxy-3-oxo-4-hexenoic acid- $\delta$-lactone) with hydrazine- $S$-methylcarbodithioate and the corresponding acid amide, thiosemicarbazide, respectively. Reaction of such Schiff bases with nickel(II) and palladium(II) ions afforded the dimeric monoligand chelates $[\mathrm{M}(\mathrm{DAE}-2 \mathrm{H})]_{2}$ and $[\mathrm{M}(\mathrm{DATS}-2 \mathrm{H})]_{2} ; \mathrm{M}=\mathrm{Ni}(\mathrm{II})$ or $\mathrm{Pd}(\mathrm{II})$. In the presence of monodentate Lewis bases, $\mathrm{B}$, square-planar chelates $[\mathrm{M}(\mathrm{DAE}-2 \mathrm{H}) \mathrm{B}]$ and $[\mathrm{M}(\mathrm{DATS}-2 \mathrm{H}) \mathrm{B}]$, in which $\mathrm{B}=$ pyridine or triphenylphosphine, were isolated. The stoichiometry and structure of the isolated organic ligands and their chelates were confirmed through elemental analyses, molecular weight determination, and infrared, ultraviolet-visible, and ${ }^{1} \mathrm{H}$ and ${ }^{13} \mathrm{C}$ nuclear magnetic resonance spectroscopy.
\end{abstract}

Abdulla Al Kubaisi et Kamal Z. Ismail. Can. J. Chem. 72, 1785 (1994).

On a isolé les bases de Schiff DAE (1) et DATS (2) de l'acide déhydroacétique en faisant réagir l'acide déhydroacétique $(\delta$ lactone de l'acide 2-acétyl-5-hydroxy-3-oxo-hex-4-ènoïque) avec l'hydrazine du carbodithioate de $S$-méthyle et l'amide correspondant, la thiosemicarbazide, respectivement. Les réactions de telles bases de Schiff avec des ions nickel(II) et palladium(II) fournissent les chélates dimères monocoordinés $[\mathrm{M}(\mathrm{DAE})-2 \mathrm{H})]_{2}$ et $\left.[\mathrm{M}(\mathrm{DATS})-2 \mathrm{H})\right]_{2}$ dans lesquels $\mathrm{M}=\mathrm{Ni}(\mathrm{II})$ ou $\mathrm{Pd}(\mathrm{II})$. En présence des bases de Lewis monocoordinées, $B$, on isole des chélates plans carrés $[\mathrm{M}(\mathrm{DAE})-2 \mathrm{H}) \mathrm{B}]_{2}$ et $\left.[\mathrm{M}(\mathrm{DATS})-2 \mathrm{H}) \mathrm{B}\right]_{2}$ dans lesquels $\mathrm{B}=$ pyridine ou triphénylphosphine. On a déterminé la stoechiométrie et la structure des coordinats organiques isolés en faisant appel à des analyses élémentaires, des déterminations de masses moléculaires et à des spectres infrarouges, ultravioletvisible et résonance magnétique nucléaire du ${ }^{1} \mathrm{H}$ et du ${ }^{13} \mathrm{C}$.

[Traduit par la rédaction]

\section{Introduction}

Dehydroacetic acid, DA, is an important and biologically active compound. Studies have shown that the compound has both antibiotic and fungicidal effects (1). In aqueous solutions, even at very low concentrations $(0.02-0.2 \%)$, DA shows a strong antiseptic effect (2). The compound is widely used in food technology. It is used to enhance vitamin C stability and protect vegetables during food processing (3) and as a preservative in such products as fish sausages (4). Above all, the structure of DA appeals to inorganic chemists working in the field of coordination chemistry.

On the other hand, hydrazinecarbodithioates and the corresponding acid amide, thiosemicarbazide, and their corresponding Schiff bases show very interesting biological properties, such as antitumour $(5,6)$, antibacteria $(7)$, and antiviral activities, in addition to a wide range of chemotherapeutic activities. Coordination of such compounds with metal ions such as nickel, iron, and copper often enhances their activity $(7,8)$, as reported for pathogenic fungi (9).

The antifungal activity of thiosemicarbazones and their corresponding metal chelates is substitution dependent, mainly upon the chemical nature of the segment attached to the $\mathrm{C}=\mathrm{S}$ carbon atom (10-13). Similarly, substitution in the ring system of Schiff bases derived from compounds containing carbonyl groups attached to $\mathrm{N}$-heterocyclic ring systems, thiosemicarbazides, and their corresponding metal chelates highly affects the biological activity of these compounds $(13,14)$. So, there is an important structure-activity relationship in these systems. In this manuscript, we use the carbonyl compound, DA, which is reported to have some biological activity, to form Schiff bases with both hydrazinecarbodithioate and thiosemicarbazide. The prepared Schiff bases may show enhanced biological activity.

\footnotetext{
${ }^{1}$ Author to whom correspondence may be addressed.

${ }^{2}$ Revision received April 5, 1994.
}

The corresponding nickel(II) and palladium(II) chelates were also prepared. We used elemental analyses and different spectroscopic techniques to elucidate both stoichiometry and structure for all isolated compounds. In future work we aim, with the assistance of our Zoology Department, to test our compound for biological activity.

\section{Results and discussion}

The reaction, in boiling ethanol, of hyrazine- $S$-methylcarbodithioate and its corresponding acid amide, thiosemicarbazide, with dehydroacetic acid, 2-acetyl-5-hydroxy-3-oxo-4hexenoic acid- $\delta$-lactone, afforded the corresponding Schiff bases DAE (1) and DATS (2), respectively (Scheme 1). Mass spectrometry fragmentation patterns as well as the infrared spectroscopic data revealed that condensation took place with the branched carbonyl group of the heterocyclic ring system of dehydroacetic acid. When mixed with metal acetates, compounds 1 and 2 reacted as dibasic tridentate anionic ligands. The coordination centres are the oxygen atom of the ring carbonyl, the sulphur atom, and the imine nitrogen [ONS] ${ }^{2-}$.

Reaction of nickel(II) acetate with DAE and DATS in the molar ratio 1:1 gave brown crystalline chelates of stoichiometry $[\mathrm{Ni}(\mathrm{DAE}-2 \mathrm{H})]_{2}$ and $[\mathrm{Ni}(\mathrm{DATS}-2 \mathrm{H})]_{2}$, respectively, where (DAE-2H), and (DATS-2H) are the dinegative anion forms of the ligands DAE and DATS, respectively. The corresponding palladium chelates $[\mathrm{Pd}(\mathrm{DAE}-2 \mathrm{H})]_{2}$ and $[\mathrm{Pd}(\mathrm{DATS}-2 \mathrm{H})]_{2}$ were similarly isolated as orange solids. Elemental analyses of these chelates (Table 1) showed monoligand metal chelate stoichiometry, i.e., one ligand per metal center. Since our ligands 1 and 2 are only tridentate, one should expect dimerization to complete the coordination. The solution electronic spectra in $\mathrm{CHCl}_{3}$ (Table 2) show several absorption bands. The uv absorption bands between ca. 270 and $320 \mathrm{~nm}$ are assigned to localized LL* transitions of the dianion form of the ligands (in alkaline solution, the unchelated ligand absorbs at ca. 280 and $320 \mathrm{~nm}$ ). 


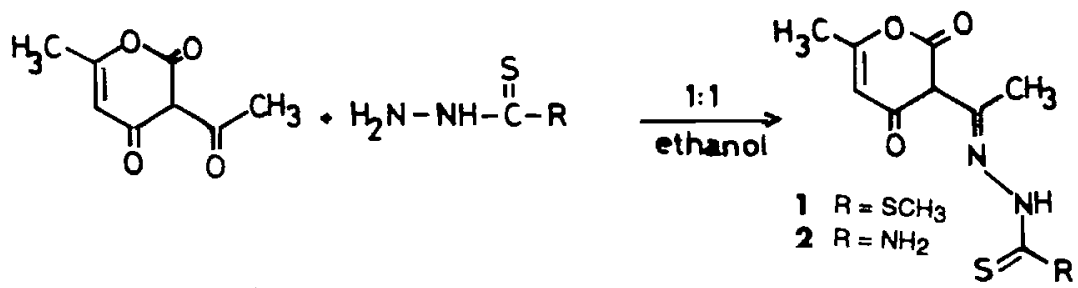
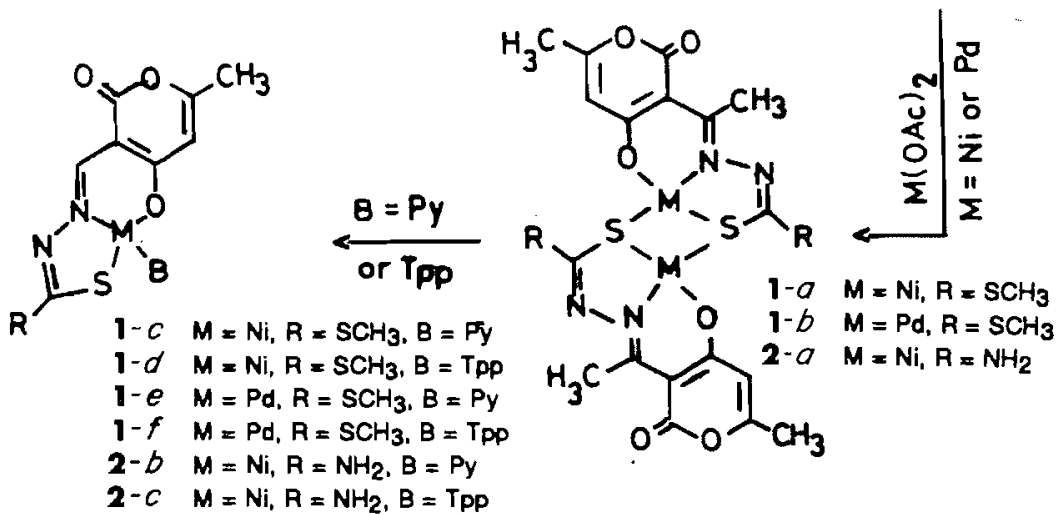

SCHEME 1

TABLE 1. Elemental analysis of DAE and DATS and their metal chelates

\begin{tabular}{|c|c|c|c|c|c|c|c|c|c|c|}
\hline \multirow{2}{*}{\multicolumn{2}{|c|}{ Compounds }} & \multicolumn{9}{|c|}{ Found (calculated) $\%$} \\
\hline & & $\mathrm{C}$ & & $\mathrm{H}$ & & $\mathrm{N}$ & & $S$ & & $\mathcal{M}$ \\
\hline 1 & DAE & $44.11(44.40)$ & 4.41 & $(4.31)$ & 10.29 & $(10.22)$ & 23.55 & $(24.05)$ & - & - \\
\hline $1 a$ & {$[\mathrm{Ni}(\mathrm{DAE}-2 \mathrm{H})]_{2}$} & $36.47(37.47)$ & 3.40 & $(3.60)$ & 8.51 & $(7.91)$ & 19.45 & $(19.51)$ & 17.9 & $(18.20)$ \\
\hline $1 c$ & [Ni(DAE-2H)Py] & $44.11(44.39)$ & 3.67 & $(3.69)$ & 10.30 & $(10.36)$ & 15.68 & $(16.16)$ & 14.38 & $(14.53)$ \\
\hline $1 d$ & [Ni(DAE-2H)Tpp] & $56.90(57.25)$ & 4.23 & $(4.26)$ & 4.73 & $(4.85)$ & 10.82 & $(10.90)$ & 9.93 & $(9.98)$ \\
\hline $1 b$ & {$[\mathrm{Pd}(\mathrm{DAE}-2 \mathrm{H})]_{2}$} & $31.83(31.62)$ & 2.65 & $(2.60)$ & 7.42 & (7.33) & 16.97 & $(16.19)$ & 28.11 & (27.94) \\
\hline $1 e$ & [Pd(DAE-2H)Py] & $39.47(39.19)$ & 3.28 & $(3.26)$ & 9.21 & $(9.05)$ & 14.03 & $(13.74)$ & 23.33 & $(23.00)$ \\
\hline $1 f$ & [Pd(DAE-2H)Tpp] & $52.66(52.92)$ & 3.91 & $(4.04)$ & 4.38 & $(4.05)$ & 10.03 & $(10.08)$ & 16.67 & $(16.96)$ \\
\hline 2 & DATS & $44.81(45.19)$ & 4.56 & $(4.27)$ & 17.42 & $(17.01)$ & 13.27 & $(12.91)$ & - & - \\
\hline $2 a$ & {$[\mathrm{Ni}(\mathrm{DATS}-2 \mathrm{H})]_{2}$} & $36.24(36.14)$ & 3.02 & $(2.80)$ & 14.07 & $(13.27)$ & 10.73 & $(10.21)$ & 17.71 & $(17.46)$ \\
\hline $2 b$ & [Ni(DATS-2H)Py] & $44.56(44.41)$ & 3.71 & $(3.71)$ & 14.85 & $(14.13)$ & 8.48 & $(8.05)$ & 15.59 & (15.61) \\
\hline $2 c$ & [Ni(DATS-2H)Tpp] & $57.85(56.90)$ & 4.28 & $(4.11)$ & 7.5 & $(7.00)$ & 5.71 & $(5.70)$ & 10.53 & $(11.20)$ \\
\hline
\end{tabular}

The absorption around $370 \mathrm{~nm}$ is due to a charge transfer transition, whereas the $d-d$ transition absorption manifold appears at ca. $460-510 \mathrm{~nm}$. No absorption bands appeared beyond $550 \mathrm{~nm}$, which is consistent with square-planar arrangements around the metal ion (15). Such arrangements can only be achieved through dimerization of the monoligand metal chelates (16), which was confirmed by determination of the molecular weights of the isolated chelates using freezing point depression. The reaction of these dimeric chelates with monodentate Lewis bases such as pyridine (Py) and triphenylphosphine (Tpp) in ethanol gave adducts of the general formula [M(DAE-2H)B] and [M(DATS$2 \mathrm{H}) \mathrm{B}$ ], where $\mathrm{B}$ is the monodentate Lewis base. The elemental analyses of the isolated compounds and their electronic spectra in $\mathrm{CHCl}_{3}$, which are consistent with the square-planar structure, as well as their infrared spectra confirm the proposed structure for these chelates.

The infrared spectra of both ligands and selected metal chelates are listed in Table 2. The spectra of the chelates show no absorption bands corresponding to $\nu \mathrm{N}-\mathrm{H}$ and $\nu \mathrm{C}=\mathrm{S}$ (the two absorption bands appear at ca. $3100 \mathrm{~cm}^{-1}$ and $1530 \mathrm{~cm}^{-1}$, respectively, in the free ligand), implying tautomerization followed by deprotonation of the thiol tautomer form of the ligand during complex formation. The spectra of the ligands, however, display a sharp $\nu \mathrm{C}=\mathrm{O}$ absorption band at ca. $1700 \mathrm{~cm}^{-1}$ confirming that the condensation takes place on the side-chain carbonyl group of the acid; otherwise, two distinct bands would have been observed due to nonequivalent ring and side-chain carbonyl groups. The palladium center in $1 a, \mathbf{1} b$, and $1 f$ exhibits a stronger tendency to shift the aromatic $\nu \mathrm{C}=\mathrm{C}$ towards $\nu \mathrm{C}=\mathrm{O}$ than does nickel in the analogous chelates. Because of nearby conjugation created by complex formation, the $\nu \mathrm{C}=\mathrm{N}$ at ca. $1540 \mathrm{~cm}^{-1}$ is shifted about $100 \mathrm{~cm}^{-1}$ towards lower frequencies.

The isolated ligands and their corresponding chelates were studied by both ${ }^{1} \mathrm{H}$ and ${ }^{13} \mathrm{C} \mathrm{nmr}$ spectroscopy. In their ${ }^{1} \mathrm{H} \mathrm{nmr}$ spectra, both ligands $\mathbf{1}$ and $\mathbf{2}$ showed two signals in the methyl region. The first, at $\delta 2.25 \mathrm{ppm}$, is due to $-\mathrm{N}=\mathrm{C}_{-} \mathrm{CH}_{3}$ methyl and the second, at $\delta 2.6 \mathrm{ppm}$, is due to $\mathrm{OCCH}_{3}$ protons. A third signal in 1 at $\delta 2.5 \mathrm{ppm}$ is attributed to the methyl ester, $\mathrm{SCH}_{3}$. While no significant shifts were observed with the first and sec- 
TABLE 2. Electronic and selected infrared spectral data for ONS ligands and some metal chelates

\begin{tabular}{|c|c|c|c|c|c|c|c|c|c|c|c|}
\hline \multirow[b]{3}{*}{1} & \multirow{3}{*}{$\begin{array}{l}\text { Compounds } \\
\text { DAE }\end{array}$} & \multirow{2}{*}{\multicolumn{3}{|c|}{$\begin{array}{l}\text { Band maxima, } \mathrm{nm} \\
\left(\log \varepsilon, \mathrm{M}^{-1} \mathrm{~cm}^{-1}\right)\end{array}$}} & & & \multicolumn{5}{|c|}{ Infrared spectral bands, $\mathrm{cm}^{-1}$} \\
\hline & & & & & & & \multirow{2}{*}{$\frac{(\mathrm{N}-\mathrm{H})}{3190}$} & \multirow{2}{*}{$\frac{(\mathrm{C}-\mathrm{N})}{1647}$} & \multirow{2}{*}{$\frac{(\mathrm{C}=\mathrm{O})}{1697}$} & \multirow{2}{*}{$\begin{array}{l}(\mathrm{C}=\mathrm{S}) \\
1547\end{array}$} & \multirow{2}{*}{$\frac{(C-C)}{1647}$} \\
\hline & & $\begin{array}{l}252 \\
(4.16)\end{array}$ & $\begin{array}{l}285 \\
(4.10)\end{array}$ & $\begin{array}{l}373 \\
(4.37)\end{array}$ & & & & & & & \\
\hline $1 a$ & {$[\mathrm{Ni}(\mathrm{DAE}-2 \mathrm{H})]_{2}$} & $\begin{array}{l}276 \\
(4.49)\end{array}$ & $\begin{array}{l}328 \\
(4.03)\end{array}$ & $\begin{array}{l}386 \\
(4.16)\end{array}$ & $480 \mathrm{sh}$ & & & 1537 & 1678,1666 & & 1645 \\
\hline $1 c$ & [Ni(DAE-2H)Py] & $\begin{array}{l}274 \\
(4.28)\end{array}$ & $320 \mathrm{sh}$ & $\begin{array}{l}460 \mathrm{sh} \\
(4.07)\end{array}$ & 480 & 510 sh & & 1541 & 1683 & & 1655 \\
\hline $1 d$ & {$[\mathrm{Ni}(\mathrm{DAE}-2 \mathrm{H}) \mathrm{T} p \mathrm{p}]$} & $\begin{array}{l}278 \\
(4.45)\end{array}$ & $\begin{array}{l}328 \\
(4.43)\end{array}$ & $\begin{array}{l}374 \\
(4.12)\end{array}$ & $460 \mathrm{sh}$ & 480 sh & & 1539 & 1701 & & 1655 \\
\hline $1 e$ & [Pd(DAE-2H)Py] & $\begin{array}{l}260 \\
(4.50)\end{array}$ & $\begin{array}{l}314 \mathrm{sh} \\
(4.15)\end{array}$ & 375 & 510 sh & & & & & & \\
\hline 2 & DATS & $\begin{array}{l}226 \\
(3.54)\end{array}$ & $\begin{array}{l}276 \\
(3.44)\end{array}$ & $\begin{array}{l}315 \\
(3.58)\end{array}$ & & & 3190 & 1628 & 694 & 1537 & 1628 \\
\hline $2 a$ & {$[\mathrm{Ni}(\mathrm{DATS}-2 \mathrm{H})]_{2}$} & $\begin{array}{l}242 \\
(4.5)\end{array}$ & $\begin{array}{l}376 \\
(3.97)\end{array}$ & $490 \mathrm{sh}$ & & & & 1529 & 1691 & & 1651 \\
\hline $2 b$ & [Ni(DATS-2H)Py] & $\begin{array}{l}240 \\
(4.4)\end{array}$ & $\begin{array}{l}263 \\
(5.35)\end{array}$ & $\begin{array}{l}370 \\
(4.64)\end{array}$ & 460 sh & & & 1529 & 1686 & & 1651 \\
\hline
\end{tabular}

TABLE 3. The ${ }^{1} \mathrm{H}$ nmr spectra of ligands and metal chelates in $\mathrm{CDCl}_{3}$

\begin{tabular}{|c|c|c|c|c|c|c|}
\hline & \multirow[b]{2}{*}{ Compound } & \multicolumn{5}{|c|}{$\delta, \mathrm{ppm}$} \\
\hline & & $\mathrm{SCH}_{3}$ & $\mathrm{CN}=\mathrm{C}-\mathrm{CH}_{3}$ & $\mathrm{OC}-\mathrm{CH}_{3}$ & $\mathrm{CH}$ & NH \\
\hline 1 & DAE & 2.5 & 2.25 & 2.6 & 5.96 & 9.87 \\
\hline $1 a$ & {$[\mathrm{Ni}(\mathrm{DAE}-2 \mathrm{H})]_{2}$} & 2.6 & 2.3 & 3.3 & 5.7 & \\
\hline $1 c$ & [Ni(DAE-2H)Py] & 2.5 & 2.1 & 2.8 & 5.7 & \\
\hline $1 d$ & [Ni(DAE-2H)Tpp] & 2.5 & 2.0 & 2.95 & 5.1 & \\
\hline $1 e$ & {$[\mathrm{Pd}(\mathrm{DAE}-2 \mathrm{H}) \mathrm{Py}]$} & 2.65 & 2.15 & 2.9 & 5.9 & \\
\hline $1 f$ & {$[\mathrm{Pd}(\mathrm{DAE}-2 \mathrm{H}) \mathrm{Tpp}]$} & 2.55 & 2.1 & 2.9 & 5.4 & \\
\hline 2 & DATS & & 2.15 & 2.55 & 6.0 & 9.9 \\
\hline $2 a$ & {$\left[\mathrm{Ni}(\mathrm{DATS}-2 \mathrm{H})_{2}\right.$} & & 2.5 & 3.45 & 5.7 & \\
\hline $2 b$ & [Ni(DATS-2H)Py] & & 2.0 & 3.3 & 5.75 & \\
\hline $2 c$ & [Ni(DATS-2H)Tpp] & & 2.0 & 3.3 & 5.1 & \\
\hline
\end{tabular}

ond signals as a result of metal chelation or adduct formation, the third signal suffered downfield shifts upon chelation and was more sensitive to the nature of the base in the isolated adducts. The disappearance of the proton signal of both the $\mathrm{C}-\mathrm{H}$ (the parafinic ring $\mathrm{CH}$ ) and the $\mathrm{N}-\mathrm{H}$ (they appear at $\delta 7.2$ and $\delta 9.82$ ppm in the free ligands) on chelation, along with the stoichiometry, confirms the dibasic tridentate nature of both ligands in their chelation. The olefinic proton shift was incoming basedependent, with triphenylphosphine causing a larger upfield shift than pyridine. The notable shielding with triphenylphosphine may be attributed to a virtual effect, from the three sterically hindered phenyl groups. The pyridine base exhibited three symmetrical proton environments showing a doublet at $\mathrm{ca} . \delta 8.7$ ppm of the $\alpha-\mathrm{CH}$ proton, a triplet centered at ca. $\delta 7.9 \mathrm{ppm}$ of the $\gamma-\mathrm{CH}$, and a triplet at ca. $\delta 7.4 \mathrm{ppm}$ of the $\beta-\mathrm{CH}$. The $\alpha-\mathrm{CH}$ proton appeared downfield shifted with respect to the other protons and further splittings were observed upon resolution-enhanced measurements, uncovering a long-range coupling between the remote protons. The nature of the metal ion did not significantly affect the pyridine proton chemical shifts. However, slight downfield shifts were observed upon replacing the $-\mathrm{SCH}_{3}$ with $-\mathrm{NH}_{2}$. The dispersion of proton chemical shifts of the pyridine hydrogens was not observed for the phenyl protons of triphenylphosphine base in the isolated adducts. Only two wide unresolved bands centered at ca. $\delta 7.4 \mathrm{ppm}$ and $\delta 7.75 \mathrm{ppm}$ were detected, due to phenyl protons for both Ni(II) and $\mathrm{Pd}(\mathrm{II})$ chelates. The ${ }^{1} \mathrm{H}$ nmr data are listed in Table 3.

The ${ }^{13} \mathrm{C}$ nmr spectra of some selected chelates were recorded for comparison. The discussion is confined to carbon nuclei whose chemical shift is affected by complex formation. Upon complexation and regardless of the nature of base, both $\mathrm{SCH}_{3}$ and $\mathrm{NC}-\mathrm{CH}_{3}$ signals were deshielded by ca. $2.5 \mathrm{ppm}$ due to donation of electron density from $\mathrm{S}$ and $\mathrm{N}$ atoms as a result of coordination to the central metal ion. The ${ }^{13} \mathrm{C}$ nmr chemical shifts of compounds 1 and $\mathbf{2}$ are almost identical. Replacement of the $-\mathrm{SCH}_{3}$ by $-\mathrm{NH}_{2}$ in 2 caused an upfield shift for the $\mathrm{C}=\mathrm{S}$ carbon by ca. $4.5 \mathrm{ppm}$ due to shielding effects by back-donation from the $\mathrm{N}$ atom. Deprotonation of the $\mathrm{OC}-\mathrm{CH}-\mathrm{CO}$ carbon is unmistakably deduced by ${ }^{13} \mathrm{C} \mathrm{nmr}$; the $\mathrm{OC}-\mathrm{CH}-\mathrm{CO}$ carbon signal observed at ca. $97 \mathrm{ppm}$ in the free ligands is severely shifted upon complexation. The conjugation in the ring system, resulting from complexation, severely deshielded the $\mathrm{OC}-\mathrm{CH}-\mathrm{CO}$ carbon. In general, coordinated triphenylphosphine exhibits a deshielding effect on the $C$-S and $C$-O-M carbons, due to its higher electron-withdrawing ability than is the case with pyridine.

\section{Experimental}

Preparation of organic ligands and their chelates

Preparation of ammonium hydrazinecarbodithioate (17)

The ammonium hydrazinecarbodithioate was prepared by treating 
hydrazine hydrate $(100 \%, 1.0 \mathrm{~mol})$, in absolute ethanol $(300 \mathrm{~mL})$, with concentrated ammonium hydroxide $(50 \mathrm{~mL})$ in a 1 -L beaker. The reaction mixture was cooled to $5^{\circ} \mathrm{C}$ in an ice bath and stirred for $15 \mathrm{~min}$ using a mechanical stirrer. The equivalent molar ratio of carbon disulphide $(1.0 \mathrm{~mol})$ was added dropwise. The reaction mixture was constantly stirred after each addition and the temperature was kept at or below $5^{\circ} \mathrm{C}$. The white product was filtered off, washed with ethanol and ether, and dried.

Preparation of S-methylhydrazinecarbodithioate (18)

An aqueous solution of ammonium hydrazinecarbodithioate $(12.5 \mathrm{~g}$, $0.1 \mathrm{~mol}$, in $100 \mathrm{~mL}$ water) was strongly shaken with methyl iodide (14.5 g, $0.1 \mathrm{~mol})$. The latter was added in small portions and the mixture was shaken after each addition. The product was filtered off, washed with water, dried, and recrystallized from benzene - petroleum ether $\left(\mathrm{mp}=82^{\circ} \mathrm{CC}\right)$.

\section{Preparation of Schiff bases}

A mixture of $0.1 \mathrm{~mol}$ of dehydroacetic acid and $0.1 \mathrm{~mol}$ of $S$-methylhydrazinecarbodithioate or thiosemicarbazide in ethanol was refluxed for $1 \mathrm{~h}$. On evaporation and cooling, the corresponding Schiff bases 1 and 2 were isolated as yellowish solids.

\section{Preparation of metal chelates}

A clear hot solution of metal acetate $(0.01 \mathrm{~mol})$ in ethanol was mixed with a boiling solution of the Schiff base $(0.01 \mathrm{~mol})$ and the mixture was refluxed for ca. $2 \mathrm{~h}$. The reaction mixture was then evaporated and cooled to yield the corresponding dimeric chelates, $[\mathrm{M}(\mathrm{DAE}-2 \mathrm{H})]_{2}$ and $[\mathrm{M}(\mathrm{DATS}-2 \mathrm{H})]_{2}$. The corresponding adducts were prepared by treating the resulting adducts $[\mathrm{M}(\mathrm{DAE}-2 \mathrm{H}) \mathrm{B}]$ and $[\mathrm{M}(\mathrm{DATS}-2 \mathrm{H}) \mathrm{B}]$ where B $=$ Py or Tpp.

\section{Measurements}

The electronic spectra were recorded in chloroform on a PerkinElmer S22 spectrophotometer. Infrared spectra were measured in the solid state using the $\mathrm{KBr}$ disk technique and a Nicolet FT-IR 5IOP spectrometer. The ${ }^{1} \mathrm{H}$ and ${ }^{13} \mathrm{C} \mathrm{nmr}$ spectra were measured on a 100 $\mathrm{MHz}$ Bruker nuclear magnetic resonance spectrometer. Finally, the formation of dimeric chelates was confirmed by determining the molecular weights cryoscopically by measuring the freezing point depression of nitrobenzene solution containing a known amount of the solute. The molal freezing point depression constant $\left(K_{\mathrm{f}}=7.00^{\circ} \mathrm{C} / \mathrm{molal}\right)$ for nitrobenzene was determined using benzil as a standard.

\section{Acknowledgement}

The authors would like to thank Professor Ahmed A. ElToukhy for his assistance during this research work.

1. K. Kakemi, T. Arita, M. Sezaki, and T. Kiriyama. Yakuzaigaku, 18, 77 (1958)

2. Y. Kato, M. Sugrura, and H. Yamada. Gifu Yakka Daigaku Kiyo, 8, 37 (1958).

3. Wm. A. Sistrunk. Food Technol. 11, 336 (1957).

4. S. Tanaka. Kolumin Eissei, 25, 138 (1956)

5. M. Das and S.E. Livingstone. Inorg. Chim. Acta, 19, 5 (1976).

6. M. Mohan, A. Agarwal, and N.K. Jha. J. Inorg. Biochem. 34, 41 (1981).

7. A. Maiti, A.K. Guha, and S. Gosh. J. Inorg. Biochem. 33, 57 (1988)

8. M. Das and S.E. Livingstone. J. Cancer, 37, 463 (1978).

9. L. Sacconi. Trans. Met. Chem. (NY), 4 (1969).

10. D.X. West, C.S. Carlson, A.C. Whyte, and E.E. Liberta. Transition Met. Chem. (London), 15, 43 (1990).

11. D.X. West, C.S. Carlson, G.P. Golloway, and C.R. Daniel. Transition Met. Chem. (London), 15, 91 (1990).

12. D.X. West, C.S. Carlson, A.E. Liberta, and C.R. Daniel. Transition Met. Chem. (London), 15, 341 (1990).

13. D.X. West, C.S. Carlson, A.E. Liberta, and J.P. Scovill. Transition Met. Chem. (London), 15, 383 (1991).

14. D.X. West, C.S. Carlson, K.J. Bouck, and A.E. Liberta. Transition Met. Chem. (London), 16, 271 (1991).

15. M. Akbar Ali, S.E. Livingstone, and D.J. Phillips. Inorg. Chem. Acta, 7, 179 (1973).

16. L.A. Sargan, E. Anckel, and Krishnamurthi. Biochem. Pharmacol. 30, 1595 (1981).

17. C.D. Johnsen, A.R. Katritzky, B.J. Ridgewell, N. Shakir, and H.N. White. Tetrahedron, 21, 1055 (1965).

18. L. El-Sayed, M.F. Iskander, and A. El-Toukhy. J. Inorg. Nucl. Chem. 36, 1739 (1974). 